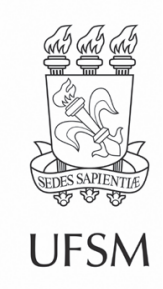

\title{
Artigos
}

\section{Variações pedológicas influenciam a composição florístico-estrutural de florestas aluviais?}

\author{
Do soil variations influence the floristic-structural composition of alluvial \\ forests?
}

\author{
André Luís Pasdioral ${ }^{\oplus}$, Daiane Cristina Dall Agnol Ceni" ${ }^{\circ}$, \\ Marília Borgo'II $\odot$, Gustavo Ribas Curcio'v ${ }^{\circ}$, Edilaine Duarte ${ }^{\prime \prime}$, \\ Amanda Köche Marcon" ${ }^{\oplus}$, Franklin Galvão" ${ }^{\oplus}$ \\ 'Prefeitura Municipal de Curitiba, Curitiba, PR, Brasil \\ "Universidade Federal do Paraná, Curitiba, PR, Brasil \\ "'Sociedade Chauá, Campo Largo, PR, Brasil \\ IVEmpresa Brasileira de Pesquisa Agropecuária, Colombo, PR, Brasil
}

\section{RESUMO}

Este estudo buscou investigar se a composição florístico-estrutural de uma floresta aluvial é influenciada pelas variações pedológicas e se há baixa diversidade e similaridade florística nesses ambientes. Ainda, objetivou avaliar se, independentemente do tipo de solo, essas florestas apresentam monodominância. O estudo foi realizado às margens do rio Iguaçu, no município de Araucária, Paraná, onde foram mapeadas e demarcadas a área de ocorrência de duas classes de solo: Gleissolo Háplico Ta Distrófico típico e Neossolo Flúvico Psamítico típico. Para a análise da estrutura fitossociológica, foram instaladas em cada compartimento 10 parcelas de $10 \mathrm{~m} \times 10 \mathrm{~m}$ e monitorada a profundidade média do lençol freático. Foram amostradas 39 espécies, distribuídas em 21 famílias botânicas. Destas, somente seis espécies foram similares nos compartimentos analisados. A flutuação do lençol freático diferiu entre os compartimentos, sendo mais próximo da superfície no Gleissolo. Gymnanthes klotzschiana apresentou os maiores valores de densidade, dominância e importância em ambos os compartimentos. A segunda espécie de maior importância na área de Gleissolo foi Myrciaria tenella, e na área de Neossolo destacase Araucaria angustifolia, devido à maior profundidade do lençol freático e ao caráter não hidromórfico do solo. Os ambientes ripários apresentaram distinções florístico-estruturais, evidenciando a necessidade de compartimentação baseada em parâmetros pedológicos, obtendo-se assim um melhor entendimento da comunidade vegetal.

Palavras-chave: Ambiente ripário; Floresta Ombrófila Mista Aluvial; Gleissolo Háplico; Neossolo Flúvico 


\section{ABSTRACT}

This study aimed to investigate if the floristic-structural composition of an alluvial forest is influenced by pedological variations and if there is low floristic diversity and similarity in these environments. Furthermore, it aimed to assess whether, independently of the type of soil, these forests have monodominance. The study was carried out in the Iguaçu River, in the municipality of Araucária, Paraná state, where two soil classes were mapped and demarcated: Gleysol and Fluvisol. To analyze the phytosociological structure, we installed 10 plots of $10 \mathrm{~m} \times 10 \mathrm{~m}$ in each compartment and monitor the average depth of the water table. We sampled thirty-nine species, distributed in 21 botanical families. Of these, only six ones were similar to both compartments. The fluctuation of the water table differed between the compartments, being closer to the surface in the Gleysol. Gymnanthes klotzschiana showed the highest values of density, dominance, and importance in both compartments. The second most important species in Gleysol was Myrciaria tenella and in the Fluvisol Araucaria angustifolia stands out, due to the greater depth of the water table and the non-hydromorphic character of the soil. The riparian environments presented floristic-structural distinctions, highlighting the need for compartmentalization based on pedological parameters, thus obtaining a more detailed understanding of the plant community.

Keywords: Riparian environment; Alluvial Mixed Ombrophylous Forest; Gleysols; Fluvisols

\section{INTRODUÇÃO}

A fisionomia das formações vegetais está condicionada às características pedológicas, geológicas e climáticas de uma região (ZACARIAS et al., 2012), além de estar sujeita a uma série de distúrbios naturais e antrópicos ao longo do tempo. No Sul do Brasil, os processos de colonização, expansão agrícola e desmatamento conduziram à fragmentação e à alteração das formações do bioma Mata Atlântica, em especial das áreas cobertas por Floresta Ombrófila Mista (NASCIMENTO et al., 2011). Esse processo de devastação foi mais acentuado nas formações de planície, principalmente nas áreas de ocorrência de florestas aluviais, que se situam em posições de relevo propícias às atividades antrópicas, tendo, como consequência, alterações frequentemente profundas (ZACARIAS et al., 2012; LOEBENS et al., 2018).

Florestas aluviais ocorrem associadas aos cursos de rios, em relevo plano (NASCIMENTO et al., 2011) e apresentam importante função como corredores ecológicos, proporcionam estabilidade do regime hídrico de planícies sujeitas a inundações (SOCHER et al., 2008), retenção dos sedimentos de lavouras, dentre 
outros. Sua gênese está associada a diversos fatores hidrogeomorfológicos ainda pouco estudados (BARDDAL et al., 2004a), podendo apresentar composição florística simplificada pelo grau de hidromorfia no solo, que funcionam como um filtro para o estabelecimento de espécies, até associações complexas, em que a Araucaria, por exemplo, ocorre com maior expressividade (RODERJAN et al., 2002).

Embora o clima atual, quente e úmido, favoreça a expansão de florestas (PILLAR; VELÉZ, 2010), diversos fatores bióticos e abióticos, além de eventos estocásticos, interagem (SHIBATA et al., 2015), determinando locais mais ou menos favoráveis para o estabelecimento florestal. A distribuição, estrutura e composição de florestas aluviais é ainda mais heterogênea e está condicionada em escala local por fatores geomorfológicos, pedológicos, geológicos e pela flutuação do lençol freático (CURCIO, 2006).

No Paraná, as áreas de Floresta Ombrófila Mista Aluvial que se encontram associadas ao rio Iguaçu apresentam elevada heterogeneidade florística e fisionômica, devido à ocupação de feições geomorfológicas distintas, determinadas pelo padrão do leito do rio (BONNET et al., 2010). A forma meandrante do rio Iguaçu no primeiro e segundo planaltos origina amplas planícies com superfícies de remoção e de deposição de sedimentos, influencia o nível de drenagem dos solos e determina baixa riqueza florística na maioria dos locais, dado ao lençol freático próximo à superfície, ao microclima e à fertilidade do solo (CURCIO, 2006; BONNET et al., 2010), compondo formações particularmente adaptadas. Variações geomórficas e pedológicas associadas ao grau de hidromorfia do solo têm sido relatadas como os principais fatores determinantes da composição florístico-estrutural nestes locais (CURCIO et al., 2007).

Dentre as classes de solos que ocorrem associadas a ambientes aluviais, destacam-se os Neossolos e Gleissolos (BARDDAL et al., 2004a; CURCIO, 2006; SANTOS et al., 2018). Os gleissolos são solos minerais, formados a partir da deposição de sedimentos, caracterizados pela presença de saturação hídrica periódica ou permanente do solo (regulada pela ascensão do lençol freático), com horizonte glei 
dentro de $50 \mathrm{~cm}$ de profundidade, e apresentam forte processo de gleização, devido à solubilização e redução do ferro, que confere cores acinzentadas, esverdeadas ou azuladas ao solo; os Neossolos são solos minerais ou orgânicos, pouco desenvolvidos em relação aos processos pedogenéticos, devido à influência dos fatores de formação do solo (e.g. tempo, clima) e material de origem (composição mineral e resistência ao intemperismo) (SANTOS et al., 2018).

Poucos estudos florísticos e fitossociológicos que considerem as características pedológicas na avaliação da vegetação foram desenvolvidos em florestas aluviais no Sul do Brasil (e.g. BARDDAL et al., 2004b; ZACARIAS et al., 2012; GONÇALVES et al., 2018). Não obstante, considerando-se os impactos antrópicos sobre esses ambientes (ZACARIAS et al., 2012), estudos sobre a estrutura e florística em condições pedológicas distintas são importantes para verificar a influência do tipo de solo no estabelecimento da vegetação florestal. Dessa forma, propôs-se neste estudo caracterizar a composição florística e estrutural de um remanescente de floresta aluvial às margens do rio Iguaçu, em duas condições pedológicas, no município de Araucária, Paraná. Buscou-se responder as seguintes questões: A composição florística e estrutural é influenciada pelas variações pedológicas? Em ambientes aluviais, independentemente do tipo de solo, as florestas apresentam monodominância? Há baixa diversidade e similaridade florística nas duas condições analisadas?

\section{MATERIAL E MÉTODO}

O estudo foi conduzido em uma propriedade localizada no distrito de General Lúcio, às margens do rio Iguaçu, no município de Araucária - PR (Figura 1). O clima da região, com base na classificação de Köppen, é do tipo Cfb, com chuvas bem distribuídas ao longo do ano, temperatura média anual de $16,5^{\circ} \mathrm{C}$ e precipitação média anual de 1400 mm (ALVARES et al., 2013). A geologia do município é constituída por migmatitos nas encostas, pertencentes ao complexo cristalino de idade Pré-Cambriana, em relevo suave a ondulado. Sobre essas áreas assentaram-se sedimentos pleistocênicos da 
formação Guabirotuba, compostos por argilitos e arcósios, e o relevo varia de suave ondulado a plano. Nos ambientes de planície, a vegetação é caracterizada como Floresta Ombrófila Mista Aluvial (IBGE, 2012) e predominam solos com diferentes graus de hidromorfia, como os Organossolos, Gleissolos e os Neossolos (RODERJAN et al., 2002).

Figura 1 - Mapa da localização do Distrito General Lúcio, em Araucária, PR

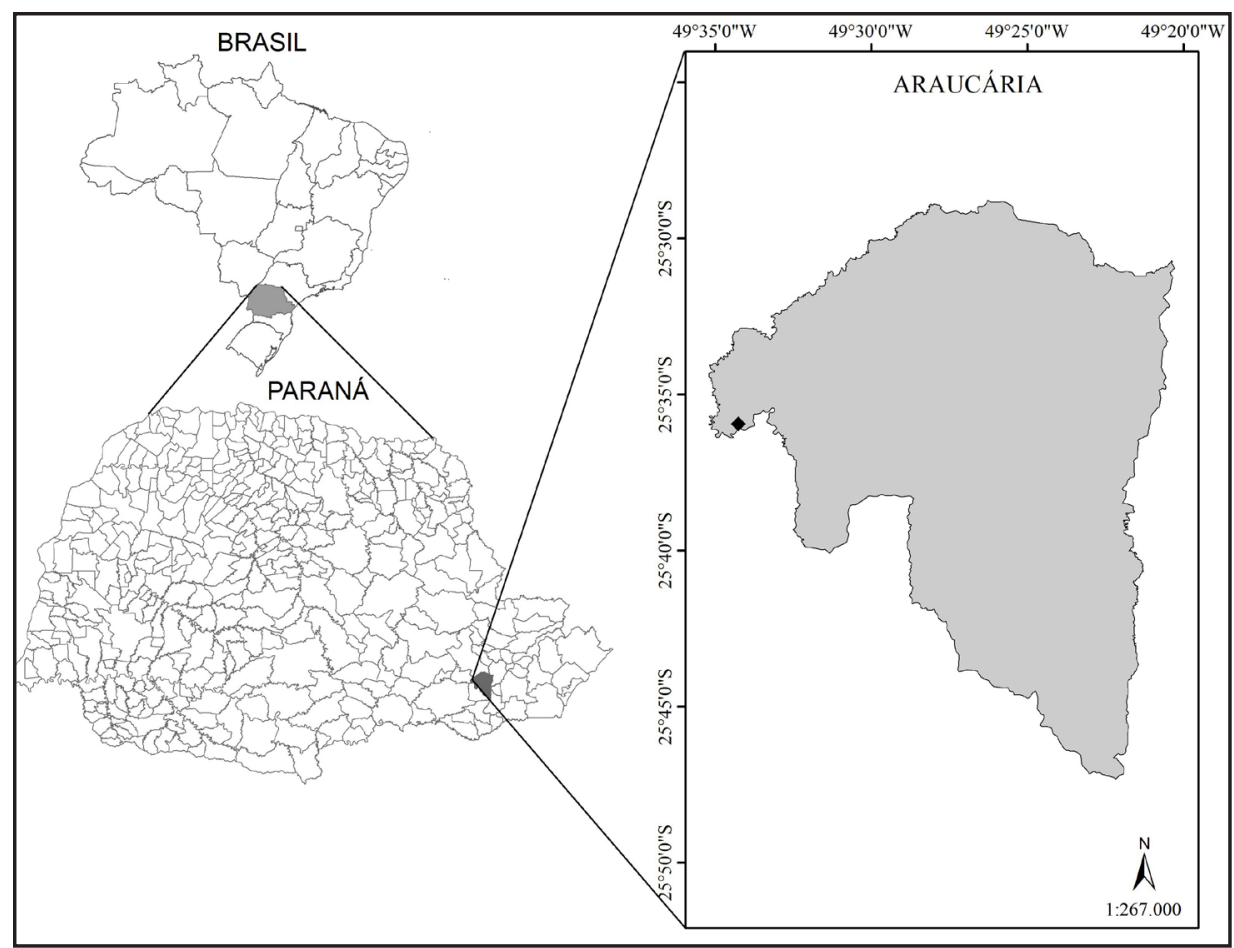

Fonte: Autores (2021)

Inicialmente, foi realizado na área de estudo o mapeamento das classes de solo em função das suas diferenças geomorfológicas (declividade e forma da rampa) e pedológicas. Para a caracterização pedológica foram abertas trincheiras de 1,5 m x 2 $\mathrm{m}$, distante cerca de $10 \mathrm{~m}$ do rio para realização da classificação morfológica (SANTOS et al., 2015). As classes de solos foram classificadas de acordo com Santos et al. (2018), em função das diferenças geomorfológicas e morfológicas ao longo da topossequência: Gleissolo Háplico Ta Distrófico típico e Neossolo Flúvico Psamítico típico. O Gleissolo Háplico Ta Distrófico típico apresentou A moderado em fase soterrada, textura 
média, estrutura moderada granular em superfície e blocos subangulares pequenos à médios em subsuperfície, consistência firme (úmido), plástica e pegajosa (molhado), apresentando fendas de contração de 0,5 a 1,3 cm nos horizontes $A_{1}(0-16 \mathrm{~cm})$ e $A_{2}$ $(0-23 \mathrm{~cm})$, os quais são recobertos por material aluvionar de cor bruno-acinzentadoescuro. Nos horizontes gleis $\mathrm{Cg}_{1}(23-40 \mathrm{~cm})$ e $\mathrm{Cg}_{2}(40-60 \mathrm{~cm})$, observou-se a presença abundante de mosqueados de cor bruno-forte, textura argilosa (micácea), estrutura fraca a moderada em blocos subangulares, pequenos, consistência firme, plástica e pegajosa. A presença dos horizontes gleis próximo à superfície evidencia a forte e constantes mudanças de potencial redox devido à recorrente ascensão do lençol freático neste compartimento.

O Neossolo Flúvico Psamítico típico, apresentou A moderado, com textura arenosa da superfície até $120 \mathrm{~cm}$ de profundidade, compreendendo os horizontes superficiais $A_{1}(0-25 \mathrm{~cm}), A_{2}(25-48 \mathrm{~cm})$, e as camadas $C_{1}(48-83 \mathrm{~cm})$ e $C_{2}(83-114 \mathrm{~cm})$, com variação de estrutura fraca a moderada, em blocos subangulares pequenos à médios, consistência friável, não pegajosa e não plástica, sendo acentuadamente drenado. Este perfil apresentou um horizonte glei Cg $(114-136 \mathrm{~cm})$, com mosqueados abundantes, médios e pequenos, distintos, de cor bruno-forte, estrutura maciça, friável, não plástico e não pegajoso. O material de origem de ambas as classes de solo é resultado do retrabalhamento de sedimentos aluviais do Holoceno, ocorrendo em relevo plano.

A partir da classificação dos solos, foram considerados dois compartimentos ambientais, sendo avaliada a composição florístico-estrutural e monitorada a profundidade do lençol freático em cada área. Dessa maneira, ao longo deste estudo, a área compreendida pelo Gleissolo Háplico Ta Distrófico típico é denominada como "compartimento Gleissolo" e a área de ocorrência da classe Neossolo Flúvico Psamítico típico como "compartimento Neossolo".

A profundidade média do lençol freático foi determinada por meio de oito poços hídricos de PVC de $6 \mathrm{~cm}$ de diâmetro $\times 140 \mathrm{~cm}$ de profundidade, perfurados a cada $5 \mathrm{~cm}$, posicionados na intersecção das parcelas, a 1,20 m de profundidade, sendo quatro em cada compartimento pedológico. As leituras foram realizadas a cada 
10 dias durante seis meses, com auxílio de uma régua graduada. A normalidade dos dados foi verificada pelo teste de Kolmogorov-Smirnov e a comparação dos dados entre os meses de cada compartimento foi realizada por meio de análise de variância, com posterior comparação das médias pelo teste de Tukey. Para comparar os valores de profundidade do lençol freático entre os compartimentos Gleissolo e Neossolo, foi realizada a análise de variância e as médias comparadas pelo teste t de Student. As análises foram realizadas com o uso da linguagem de programação R (R CORE TEAM, 2017), a 95\% de probabilidade.

Para o estudo fitossociológico, foram alocadas 20 parcelas de $10 \mathrm{~m} \times 10 \mathrm{~m}(0,2$ ha), sendo 10 em cada compartimento pedológico, com orientação paralela ao curso fluvial e distante 5 metros da margem do rio (coleta de dados realizada no ano de 2002). Em cada parcela foram coletados, identificados com plaquetas metálicas e medidos todos os indivíduos arbóreos com perímetro a altura do peito (PAP) $\geq 10 \mathrm{~cm}$. Espécies com múltiplos troncos foram incluídas quando pelo menos um dos troncos obtivesse PAP $\geq 10 \mathrm{~cm}$. Registrou-se a altura dos indivíduos, posição no estrato vertical da floresta (GALVÃO, 1994) e a presença de árvores mortas. A estrutura diamétrica foi analisada por meio de histogramas de frequência, com base na distribuição dos indivíduos em classes de diâmetro, em intervalos de $2 \mathrm{~cm}$. A identificação das espécies foi realizada por meio de comparação com exsicatas do Herbário da Escola de Florestas da Universidade Federal do Paraná (EFC) e os nomes científicos foram atualizados no site da Flora do Brasil (FLORA do Brasil 2020, [20--]).

Para cada espécie, em cadaárea, foram calculados os descritores fitossociológicos de densidade, frequência e dominância absoluta e relativa, valor de importância e valor de cobertura (EISENLOHR et al. 2015), utilizando-se o programa FITOPAC (SHEPHERD, 2010). As espécies foram agrupadas em três categorias de dispersão (anemocórica, autocórica e zoocórica) (PIJL, 1982), classificadas quanto ao grupo ecológico em pioneira e não pioneira (WHITMORE, 1989), e em relação ao grau de saturação hídrica em três fitotipias (hidrófila, higrófila e mesófila) (CURCIO et al., 2007), sendo obtidas com base em observações a campo e consulta à literatura. Para caracterizar a 
diversidade, foram calculados os índices de diversidade de Shannon e a equabilidade de Pielou por compartimento, e verificada a similaridade florística entre as classes de solo pelo índice de Jaccard. Foram verificadas as espécies indicadoras de cada classe de solo (DUFRÊNE; LEGENDRE, 1997), utilizando o pacote Labdsv (ROBERTS, 2019) e a linguagem de programação R (R CORE TEAM, 2017) (95\% e 99\% de probabilidade).

\section{RESULTADOS E DISCUSSÃO}

\subsection{Composição florística}

Para a área total, foram amostrados 607 indivíduos, pertencentes a 39 espécies e 21 famílias botânicas. Destas, duas foram identificadas em nível de gênero e duas ficaram indeterminadas (Tabela 1). Foi observada baixa similaridade florística $(11,7 \%)$ entre os compartimentos Gleissolo e Neossolo, sendo apenas seis espécies comuns aos dois ambientes (Casearia decandra, Gymnanthes klotzschiana, Lonchocarpus sp., Ocotea pulchella, Sebastiania brasiliensis e Vitex megapotamica). Com relação às espécies exclusivas, os compartimentos Gleissolo e Neossolo foram representados, respectivamente, por $16(41,0 \%)$ e $17(43,6 \%)$ espécies.

Tabela 1 - Lista de espécies e número de indivíduos amostrados nos compartimentos Gleissolo e Neossolo em Araucária - PR

\begin{tabular}{|c|c|c|c|c|c|}
\hline Família/Espécie & Gleissolo & Neossolo & GE & $\mathbf{F}$ & SD \\
\hline \multicolumn{6}{|l|}{ Anacardiaceae } \\
\hline Schinus terebinthifolia Raddi • & 11 & & $\mathrm{PI}$ & HG & ZOO \\
\hline \multicolumn{6}{|l|}{ Annonaceae } \\
\hline Annona emarginata (Schltdl.) H.Rainer & & 4 & NP & - & zOO \\
\hline \multicolumn{6}{|l|}{ Araucariaceae } \\
\hline Araucaria angustifolia (Bertol.) Kuntze & & 8 & NP & MS & ZOO \\
\hline \multicolumn{6}{|l|}{ Canellaceae } \\
\hline Cinnamodendron dinisii Schwacke & & 3 & NP & - & ZOO \\
\hline \multicolumn{6}{|l|}{ Celastraceae } \\
\hline Monteverdia ilicifolia (Mart. Ex Reissek) Biral & 1 & & NP & - & zOO \\
\hline
\end{tabular}


Tabela 1 - Continuação

\begin{tabular}{|c|c|c|c|c|c|}
\hline Família/Espécie & Gleissolo & Neossolo & GE & $\mathbf{F}$ & SD \\
\hline \multicolumn{6}{|l|}{ Erythroxylaceae } \\
\hline Erythroxylum deciduum A.St.-Hil. & 3 & & $\mathrm{PI}$ & HG & ZOO \\
\hline \multicolumn{6}{|l|}{ Euphorbiaceae } \\
\hline Gymnanthes klotzschiana Müll.Arg. * $\mathbf{\Delta}$ & 147 & 193 & $\mathrm{PI}$ & $H D$ & AUT \\
\hline Sebastiania brasiliensis Spreng. * & 5 & 1 & NP & HG & AUT \\
\hline \multicolumn{6}{|l|}{ Fabaceae } \\
\hline Erythrina crista-galli L. $\bullet$ & 9 & & $\mathrm{PI}$ & $H D$ & ZOO \\
\hline Lonchocarpus sp. * & 1 & 1 & NP & HG & - \\
\hline \multicolumn{6}{|l|}{ Lamiaceae } \\
\hline Vitex megapotamica (Spreng.) Moldenke * & 15 & 2 & NP & HG & ZOO \\
\hline \multicolumn{6}{|l|}{ Lauraceae } \\
\hline Ocotea pulchella (Nees \& Mart.) Mez * & 2 & 4 & NP & HG & ZOO \\
\hline \multicolumn{6}{|l|}{ Lythraceae } \\
\hline Lafoensia pacari A.St.-Hil. & & 2 & NP & - & ANE \\
\hline \multicolumn{6}{|l|}{ Monimiaceae } \\
\hline Mollinedia clavigera Tul. & & 9 & NP & MS & ZOO \\
\hline \multicolumn{6}{|l|}{ Myrtaceae } \\
\hline Blepharocalyx salicifolius (Kunth) O.Berg • & 14 & & NP & $H D$ & zOO \\
\hline Calyptranthes concinna DC. & & 2 & NP & MS & zOO \\
\hline Campomanesia xanthocarpa (Mart.) O.Berg & & 13 & NP & MS & zOO \\
\hline Eugenia uruguayensis Cambess. & 2 & & NP & - & ZOO \\
\hline Indeterminada 1 & & 1 & & & \\
\hline Indeterminada 2 & & 1 & & & \\
\hline Myrceugenia glaucescens (Cambess.) D.Legrand \& Kausel & 3 & & NP & - & zOO \\
\hline Myrcia guianensis (Aubl.) DC. & & 2 & NP & MS & zOO \\
\hline Myrcia laruotteana Cambess. & 7 & & NP & $H D$ & zOO \\
\hline Myrcia multiflora (Lam.) DC. & & 5 & $\mathrm{PI}$ & - & zOO \\
\hline Myrcia splendens (Sw.) DC. & & 8 & NP & MS & zOO \\
\hline Myrciaria tenella (DC.) O.Berg •• & 55 & & NP & $H D$ & zOO \\
\hline Myrrhinium atropurpureum Schott• & 12 & & NP & HG & zOO \\
\hline \multicolumn{6}{|l|}{ Picramniaceae } \\
\hline Picramnia parvifolia Engl. & 2 & & NP & - & ZOO \\
\hline \multicolumn{6}{|l|}{ Proteaceae } \\
\hline Roupala montana Aubl. & & 3 & NP & - & ANE \\
\hline \multicolumn{6}{|l|}{ Rosaceae } \\
\hline Prunus myrtifolia (L.) Urb. & & 5 & NP & - & ZOO \\
\hline
\end{tabular}


Tabela 1 - Conclusão

\begin{tabular}{|c|c|c|c|c|c|}
\hline Família/Espécie & Gleissolo & Neossolo & GE & $\mathbf{F}$ & SD \\
\hline \multicolumn{6}{|l|}{ Rubiaceae } \\
\hline Coussarea contracta (Walp.) Müll.Arg. ${ }^{\star}$ & & 14 & NP & HG & ZOO \\
\hline Guettarda uruguensis Cham. \& Schltdl. & 1 & & NP & HG & $\mathrm{ZOO}$ \\
\hline \multicolumn{6}{|l|}{ Rutaceae } \\
\hline Citrus sp. & 1 & & - & - & ZOO \\
\hline \multicolumn{6}{|l|}{ Salicaceae } \\
\hline Casearia decandra Jacq. * & 3 & 7 & NP & HG & ZOO \\
\hline Casearia obliqua Spreng. & & 1 & NP & MS & ZOO \\
\hline \multicolumn{6}{|l|}{ Sapindaceae } \\
\hline Allophylus edulis (A.St.-Hil. et al.) Hieron. Ex Niederl. • & 10 & & NP & HG & ZOO \\
\hline Cupania vernalis Cambess. & & 3 & NP & MS & ZOO \\
\hline Matayba elaeagnoides Radlk. & 3 & & NP & HG & ZOO \\
\hline \multicolumn{6}{|l|}{ Thymelaeaceae } \\
\hline Daphnopsis racemosa Griseb. • & 8 & & NP & HG & ZOO \\
\hline Indivíduos mortos & 10 & 12 & - & - & - \\
\hline Total & 325 & 304 & - & - & - \\
\hline
\end{tabular}

Fonte: Autores (2021)

Em que: $\mathrm{GE}$ = grupo ecológico (PI=pioneira, $\mathrm{NP}=$ não pioneira); $\mathrm{F}=$ fitotipias ( $\mathrm{HD}=$ hidrófila, $\mathrm{HG}=$ higrófila, $\mathrm{MS}=$ =mesófila); $\mathrm{SD}=$ síndromes de dispersão $(\mathrm{ZOO}=$ zoocoria, $\mathrm{ANE}=$ anemocoria, $\mathrm{AUT}=$ autocoria $)$. *espécies similares; •espécies indicadoras do compartimento Gleissolo $(\bullet p<0,01 ; \cdot p<0,05)$;

$\boldsymbol{\Delta}$ espécies indicadoras do compartimento Neossolo $(\boldsymbol{\bullet} p<0,05)$.

Myrtaceae foi a família de maior riqueza de espécies (13), seguida por Sapindaceae (3), Euphorbiaceae, Fabaceae e Rubiaceae (duas espécies cada). Para a abundância, a família de maior expressividade foi Euphorbiaceae, constituída pelas espécies Gymnanthes klotzschiana e Sebastiania brasiliensis, representou no compartimento Gleissolo $(46,76 \%)$ e no Neossolo $(63,81 \%)$ dos indivíduos amostrados. A Mata Atlântica é considerada um centro de endemismo para diversos grupos de Myrtaceae Neotropicais, o que explica sua grande representatividade em abundância e riqueza em estudos realizados no bioma (STEHMANN et al., 2009). Dessa maneira, Myrtaceae pode ser considerada uma família indicadora da diversidade arbórea em todas as subcategorias de vegetação da Mata Atlântica, inclusive para as florestas 
aluviais (LUCAS; BÜNGER, 2015). A maior riqueza de Myrtaceae, juntamente com a maior densidade de indivíduos de Euphorbiaceae, também foram observadas em outros estudos conduzidos em ambientes aluviais (e.g. BARDDAL et al. 2004b; LOEBENS et al., 2018).

Com relação às espécies indicadoras, no compartimento Gleissolo, destacaram-se Myrciaria tenella (valor indicador de 1,0000), Schinus terebinthifolia $(0,800)$, Daphnopsis racemosa, Erythrina crista-galli e Myrrhinium atropurpureum $(0,700)$, Blepharocalyx salicifolius $(0,600)$ e Allophylus edulis $(0,500)$. No compartimento Neossolo, as espécies que se destacaram como indicadoras foram Coussarea contracta $(0,800)$, Campomanesia xanthocarpa $(0,600)$, Gymnanthes klotzschiana $(0,567)$ e Myrcia splendens $(0,500)$. Destaca-se que a maior parte dessas espécies pertencem ao grupo ecológico das não pioneiras e são zoocóricas, reforçando a importância da interação com a fauna na dispersão de propágulos no local. A ocorrência majoritária da síndrome de dispersão zoocórica é esperada em florestas tropicais em estágio avançado de regeneração em função da maior disponibilidade de frutos, que são consumidos principalmente por pássaros e mamíferos (PIJL, 1982).

Dentre as fitotipias, destaca-se que a maior parte das espécies apresentou caráter higrófilo (apresentam desenvolvimento normal sobre solos semi-hidromórficos, moderadamente drenados) a hidrófilo (apresentam desenvolvimento normal sobre solos hidromórficos, classe imperfeitamente drenado a muito mal drenado) (CURCIO, 2006). No entanto, em ambas as áreas, independentemente do tipo de solo, houve o predomínio de Gymnanthes klotzschiana, espécie pioneira, autocórica, hidrófila, que apresenta ampla plasticidade e adaptação aos ambientes aluviais (CURCIO et al., 2006; SILVA et al., 2009; GONÇALVES et al., 2018).

A diversidade de Shannon e equabilidade de Pielou foram baixas para ambos os compartimentos, isso pode ser explicado pela elevada dominância de poucas espécies na amostragem, sendo para o compartimento Gleissolo de $\mathrm{H}^{\prime}=2,06$ e J = 0,65, e para o compartimento Neossolo $H^{\prime}=1,68$ e $J=0,53$. Resultados semelhantes foram encontrados em outros estudos conduzidos em ambientes aluviais (BARDDAL 
et al., 2004b; CURCIO et al., 2007). Barddal et al. (2004b) atribuíram a baixa diversidade à segmentação das áreas aluviais, que limitam a ocorrência de espécies a uma pequena faixa de hidromorfia do solo.

\subsection{Flutuação do lençol freático}

A profundidade do nível do lençol freático apresentou variações entre os compartimentos e meses analisados. Para o compartimento Gleissolo, o lençol freático esteve mais profundo nos meses de julho a setembro e mais próximo da superfície nos meses de outubro e novembro (Tabela 2), coincidindo com o período de maior precipitação na região devido à influência da Zona de Convergência Intertropical, que ocasiona invernos secos e verões chuvosos (GAN et al., [20--]). Já o compartimento Neossolo apresentou o lençol freático mais profundo em todos os meses analisados, o que pode estar relacionado à textura essencialmente arenosa (MACHADO et al., 2013).

Tabela 2 - Profundidade média, mínima e máxima do lençol freático entre os meses de julho/2002 a janeiro/2003 nos compartimentos Gleissolo e Neossolo

\begin{tabular}{ccccccccccc}
\hline $\begin{array}{c}\text { Profundidade do } \\
\text { lençol freático (cm) }\end{array}$ & JUL & AGO & SET & OUT & NOV & DEZ & JAN & $\begin{array}{c}\text { Média } \\
\text { geral }\end{array}$ & $\boldsymbol{p}$ \\
\hline \multirow{3}{*}{ Gleissolo } & máxima & 106,0 & 68,0 & 91,5 & 59,5 & 64,5 & 78,5 & 78,0 & & \\
& média & $110,3 \mathrm{a}$ & $85,9 \mathrm{~b}$ & $106,2 \mathrm{a}$ & $81,8 \mathrm{~b}$ & $76,6 \mathrm{~b}$ & $85,0 \mathrm{~b}$ & $87,6 \mathrm{~b}$ & 87,0 & \\
& mínima & 113,0 & 109,0 & 118,5 & 108,0 & 91,0 & 93,5 & 98,0 & & \multirow{2}{*}{0,000} \\
\multirow{2}{*}{ Neossolo } & máxima & 118,0 & 116,0 & 116,0 & 115,0 & 117,5 & 119,0 & 118,5 & & \\
& média & $119,5 \mathrm{a}$ & $118,6 \mathrm{a}$ & $117,5 \mathrm{a}$ & $118,0 \mathrm{a}$ & $119,5 \mathrm{a}$ & $119,8 \mathrm{a}$ & $119,8 \mathrm{a}$ & 118,9 \\
& mínima & 120,0 & 120,0 & 120,0 & 120,0 & 120,0 & 120,0 & 120,0 & \\
\hline
\end{tabular}

Fonte: Autores (2021)

Em que: Médias seguidas de mesma letra na linha não diferem pelo teste de Tukey, a 95\% de probabilidade. $p=p$-valor de acordo com o teste $t$ de Student, aplicado na comparação entre as médias dos dois compartimentos.

O regime hídrico influencia o reabastecimento do lençol freático, porém os níveis de flutuação são determinados pela distribuição e quantidade de escoamento superficial, altura e forma das feições geomórficas, características pedológicas (estrutura física), determinando variações na composição florística e estrutural desses ambientes (CURCIO et al., 2007; ZACARIAS et al., 2012). 


\subsection{Caracterização fitossociológica relacionada aos atributos pedológicos}

\subsubsection{Compartimento Gleissolo}

Neste compartimento foram amostrados 315 indivíduos vivos, distribuídos em 14 famílias e 22 espécies botânicas. A família de maior riqueza foi Myrtaceae (seis espécies) e de maior densidade e dominância Euphorbiaceae (152) seguida por Myrtaceae $(93$ indivíduos), as quais juntas representaram 75,4\% dos indivíduos amostrados (Tabela 3).

Gymnanthes klotzschiana foi a espécie de maior densidade (1470 ind/ha) e dominância $(26,9$ m²/ha), o que refletiu em um maior valor de importância $(119,58)$. Seguem-se a esta, para a densidade, Myrciaria tenella (550 ind/ha), Vitex megapotamica (150 ind/ha) e Blepharocalyx salicifolius (140 ind/ha), que juntas representaram $71 \% \mathrm{da}$ densidade total.

As espécies de maior dominância foram Gymnanthes klotzschiana $\left(26,9 \mathrm{~m}^{2} / \mathrm{ha}\right)$, Blepharocalyx salicifolius (4,1 $\left.\mathrm{m}^{2} / \mathrm{ha}\right)$, Schinus terebinthifolia $\left(3 \mathrm{~m}^{2} / \mathrm{ha}\right)$, Vitex megapotamica (2,5 m²/ha), Erythrina crista-galli (2,2 m²/ha), representando $90 \%$ da área basal. Com relação à frequência, apenas Gymnanthes klotzschiana e Myrciaria tenella ocorreram em todas as parcelas amostradas, Blepharocalyx salicifolius e Daphnopsis racemosa (60\%), Vitex megapotamica, Myrrhinium atropurpureum e Allophylus edulis (50\%), as demais espécies apresentaram ocorrência inferior a 40\% nas parcelas.

Gymnanthes klotzschiana também foi relatada como a espécie de maior valor de importância em outras pesquisas realizadas em ambientes aluviais no Sul do Brasil (BARDDAL et al., 2004b; CURCIO et al., 2007). Neste estudo, a classe de solo não foi mandatória para a ocorrência da espécie, visto que nos dois compartimentos ocorre a monodominância de Gymnanthes klotzschiana. A dominância desta espécie, assim como a baixa diversidade observada nos ambientes analisados, reflete a influência da dinâmica do rio, sendo as áreas sujeitas a períodos com flutuação do lençol freático, que determina um ambiente restritivo para o estabelecimento de outras espécies (LOEBENS et al., 2018). Essa espécie ocorre com maior expressividade nas planícies de 
inundação da Floresta Ombrófila Mista Aluvial, em que, frequentemente, é a espécie dominante (BARDDAL et al., 2004b; CURCIO et al. 2007; GONÇALVES et al., 2018), compondo uma fisionomia própria, muito característica.

Tabela 3 - Espécies amostradas no compartimento Gleissolo e seus respectivos descritores fitossociológicos

\begin{tabular}{|c|c|c|c|c|c|c|}
\hline Espécie & Família & DA & FA & DoA & VI & VC \\
\hline Gymnanthes klotzschiana Müll.Arg. & Euphorbiaceae & 1470 & 100 & 26,9 & 119,58 & 107,39 \\
\hline Myrciaria tenella (DC.) O.Berg & Myrtaceae & 550 & 100 & 1,2 & 31,79 & 19,6 \\
\hline Blepharocalyx salicifolius (Kunth) O.Berg & Myrtaceae & 140 & 60 & 4,1 & 20,91 & 13,59 \\
\hline Vitex megapotamica (Spreng.) Moldenke & Lamiaceae & 150 & 50 & 2,5 & 16,49 & 10,39 \\
\hline Schinus terebinthifolia Raddi & Anacardiaceae & 110 & 40 & 3 & 15,2 & 10,32 \\
\hline Erythrina crista-galli L. & Fabaceae & 90 & 30 & 2,2 & 11,54 & 7,88 \\
\hline Myrrhinium atropurpureum Schott & Myrtaceae & 120 & 50 & 0,4 & 10,65 & 4,56 \\
\hline Daphnopsis racemosa Griseb. & Thymelaeaceae & 80 & 60 & 0,2 & 10,11 & 2,8 \\
\hline $\begin{array}{l}\text { Allophylus edulis (A.St.-Hil. et al.) Hieron. Ex } \\
\text { Niederl. }\end{array}$ & Sapindaceae & 100 & 50 & 0,3 & 9,87 & 3,77 \\
\hline Myrcia laruotteana Cambess. & Myrtaceae & 70 & 40 & 0,5 & 8,11 & 3,23 \\
\hline Matayba elaeagnoides Radlk. & Sapindaceae & 30 & 30 & 0,2 & 4,89 & 1,23 \\
\hline Sebastiania brasiliensis Spreng. & Euphorbiaceae & 50 & 20 & 0,2 & 4,44 & 2,01 \\
\hline Erythroxylum deciduum A.St.-Hil. & Erythroxylaceae & 30 & 20 & 0,4 & 4,35 & 1,91 \\
\hline Casearia decandra Jacq. & Salicaceae & 30 & 20 & 0,13 & 3,67 & 1,23 \\
\hline $\begin{array}{l}\text { Myrceugenia glaucescens (Cambess.) } \\
\text { D.Legrand \& Kausel }\end{array}$ & Myrtaceae & 30 & 20 & 0,09 & 3,57 & 1,13 \\
\hline Eugenia uruguayensis Cambess. & Myrtaceae & 20 & 20 & 0,03 & 3,12 & 0,68 \\
\hline Picramnia parvifolia Engl. & Picramniaceae & 20 & 10 & 0,12 & 2,09 & 0,87 \\
\hline Ocotea pulchella (Nees \& Mart.) Mez & Lauraceae & 20 & 10 & 0,07 & 2 & 0,78 \\
\hline Lonchocarpus sp. & Fabaceae & 10 & 10 & 0,04 & 1,63 & 0,41 \\
\hline Guettarda uruguensis Cham. \& Schltdl. & Rubiaceae & 10 & 10 & 0,03 & 1,61 & 0,39 \\
\hline Monteverdia ilicifolia (Mart. Ex Reissek) Biral & Celastraceae & 10 & 10 & 0,016 & 1,56 & 0,34 \\
\hline Citrus sp. & Rutaceae & 10 & 10 & 0,014 & 1,55 & 0,33 \\
\hline Indivíduos mortos & - & 100 & 50 & 0,9 & 11,26 & 5,16 \\
\hline Total & - & 3250 & 820 & 43,41 & 300 & 200 \\
\hline
\end{tabular}

Fonte: Autores (2021)

Em que: $\mathrm{DA}$ = densidade absoluta; $\mathrm{DA}$ = frequência absoluta; $\mathrm{DoA}$ = dominância absoluta; $\mathrm{VI}$ = valor de importância; VC = valor de cobertura. 


\subsubsection{Compartimento Neossolo}

Neste compartimento foram amostrados 292 indivíduos vivos, distribuídos em 15 famílias, 23 espécies (Tabela 5). Gymnanthes klotzschiana se destaca novamente como a espécie de maior densidade (1930 ind/ha), dominância $\left(25,32 \mathrm{~m}^{2} / \mathrm{ha}\right.$ ) e valor de importância $(136,43)$ (Tabela 4). Os resultados refletem o caráter monodominante da espécie em formações aluviais, apresentando valores maiores que 50\% para os parâmetros fitossociológicos analisados (CONNEL; LOWMAN, 1989). Para a densidade, a espécie é seguida por Coussarea contracta (140 ind/ha), Campomanesia xanthocarpa (130 ind/ha), Mollinedia clavigera (90 ind./ha), Araucaria angustifolia e Myrcia splendens (80 ind./ha), representando $83 \%$ da densidade total. Para a dominância, destaca-se Araucaria angustifolia, com dominância de 12,12 m²/ha e valor de importância de 36,37, representando juntamente com Gymnanthes klotzschiana 85\% da área basal total.

Com relação à frequência, apenas Gymnanthes klotzschiana ocorreu em todas as parcelas amostradas, seguida por Casearia decandra (50\%), Araucaria angustifolia, Campomanesia xanthocarpa, Mollinedia clavigera, Myrcia splendens e Myrcia multiflora, (40\%), as demais espécies apresentaram ocorrência inferior a 40\%. Gymnanthes klotzschiana apresenta plasticidade e adaptação aos ambientes ripários, por desenvolver estratégias morfoanatômicas e metabólicas (COSMO et al., 2010), conseguindo dessa forma tolerar períodos de saturação hídrica do solo (BARDDAL et al., 2004b). A presença de espécies mesófilas nesses ambientes está condicionada ao alteamento do solo pela contínua deposição de sedimentos, em relação aos níveis de flutuação do lençol freático, sendo o crescimento e sobrevivência relacionados à adaptabilidade das espécies aos distintos regimes hídricos (CURCIO et al., 2007). A presença de Araucaria angustifolia nesta floresta aluvial está condicionada ao compartimento Neossolo, no qual o lençol freático é mais profundo e o solo não é saturado na maior parte do tempo. Dessa maneira, ao considerar, por exemplo, um projeto de revegetação de área Floresta Ombrófila Mista Aluvial, espécies como Araucaria angustifolia não devem ser empregadas em ambientes com excesso hídrico, 
pois são típicas colonizadoras de ambientes bem drenados (CURCIO et al., 2007). Assim, para se obter um melhor desenvolvimento das espécies em condições específicas de ambientes aluviais, é necessária a compartimentação ambiental de acordo com as características pedológicas e ecológicas das espécies.

Tabela 4 - Espécies amostradas no compartimento sobre Neossolo e seus respectivos descritores fitossociológicos

\begin{tabular}{|c|c|c|c|c|c|c|}
\hline Espécie & Família & DA & FA & DoA & VI & vc \\
\hline Gymnanthes klotzschiana Müll.Arg. & Euphorbiaceae & 1930 & 100 & 25,32 & 136,43 & 121,28 \\
\hline Araucaria angustifolia (Bertol.) Kuntze & Araucariaceae & 80 & 40 & 12,12 & 36,37 & 30,31 \\
\hline Campomanesia xanthocarpa (Mart.) O.Berg & Myrtaceae & 130 & 40 & 1,5 & 13,78 & 7,72 \\
\hline Casearia decandra Jacq. & Salicaceae & 70 & 50 & 0,54 & 11,13 & 3,55 \\
\hline Coussarea contracta (Walp.) Müll.Arg. & Rubiaceae & 140 & 30 & 0,48 & 10,25 & 5,7 \\
\hline Mollinedia clavigera Tul. & Monimiaceae & 90 & 40 & 0,17 & 9,42 & 3,36 \\
\hline Myrcia splendens (Sw.) DC. & Myrtaceae & 80 & 40 & 0,24 & 9,24 & 3,18 \\
\hline Myrcia multiflora (Lam.) DC. & Myrtaceae & 50 & 40 & 0,32 & 8,44 & 2,38 \\
\hline Prunus myrtifolia (L.) Urb. & Rosaceae & 50 & 30 & 0,7 & 7,8 & 3,26 \\
\hline Ocotea pulchella (Nees \& Mart.) Mez & Lauraceae & 40 & 30 & 0,74 & 7,56 & 3,01 \\
\hline Cupania vernalis Cambess. & Sapindaceae & 30 & 20 & 0,22 & 4,53 & 1,5 \\
\hline Annona emarginata (Schltdl.) H.Rainer & Annonaceae & 40 & 20 & 0,044 & 4,45 & 1,42 \\
\hline Myrcia guianensis (Aubl.) DC. & Myrtaceae & 20 & 10 & 0,3 & 2,86 & 1,35 \\
\hline Lafoensia pacari A.St.-Hil. & Lythraceae & 20 & 10 & 0,29 & 2,85 & 1,34 \\
\hline Cinnamodendron dinisii Schwacke & Canellaceae & 30 & 10 & 0,056 & 2,63 & 1,12 \\
\hline $\begin{array}{l}\text { Roupala montana var. brasiliensis (Klotzsch) } \\
\text { K.S.Edwards }\end{array}$ & Proteaceae & 30 & 10 & 0,056 & 2,63 & 1,12 \\
\hline Vitex megapotamica (Spreng.) Moldenke & Lamiaceae & 20 & 10 & 0,043 & 2,27 & 0,76 \\
\hline Calyptranthes concinna DC. & Myrtaceae & 20 & 10 & 0,036 & 2,26 & 0,74 \\
\hline Lonchocarpus sp. & Fabaceae & 10 & 10 & 0,046 & 1,95 & 0,44 \\
\hline Sebastiania brasiliensis Spreng. & Euphorbiaceae & 10 & 10 & 0,038 & 1,93 & 0,42 \\
\hline Indeterminada 1 & Myrtaceae & 10 & 10 & 0,011 & 1,87 & 0,35 \\
\hline Indeterminada 2 & Myrtaceae & 10 & 10 & 0,0096 & 1,87 & 0,35 \\
\hline Casearia obliqua Spreng. & Salicaceae & 10 & 10 & 0,008 & 1,86 & 0,35 \\
\hline Indivíduos mortos & - & 120 & 70 & 0,45 & 15,6 & 5 \\
\hline Total & - & 3040 & 660 & 43,73 & 300 & 200 \\
\hline
\end{tabular}

Fonte: Autores (2021)

Em que: $\mathrm{DA}$ = densidade absoluta; $\mathrm{DA}$ = frequência absoluta; $\mathrm{DoA}=$ dominância absoluta; $\mathrm{VI}$ = valor de importância; $\mathrm{VC}=$ valor de cobertura. 


\subsection{Distribuição diamétrica e estratificação vertical}

Os compartimentos pedológicos apresentaram indivíduos com diâmetro a altura do peito (DAP) médio de 3,2 cm e distribuição diamétrica do tipo "J" invertido, em que a maioria dos indivíduos se encontram nas menores classes de diâmetro, ou seja, maior estoque de indivíduos jovens na floresta, e poucos indivíduos com DAP maiores (Figura 2).

Figura 2 - Distribuição diamétrica dos indivíduos amostrados nos compartimentos Gleissolo (A) e Neossolo (B)

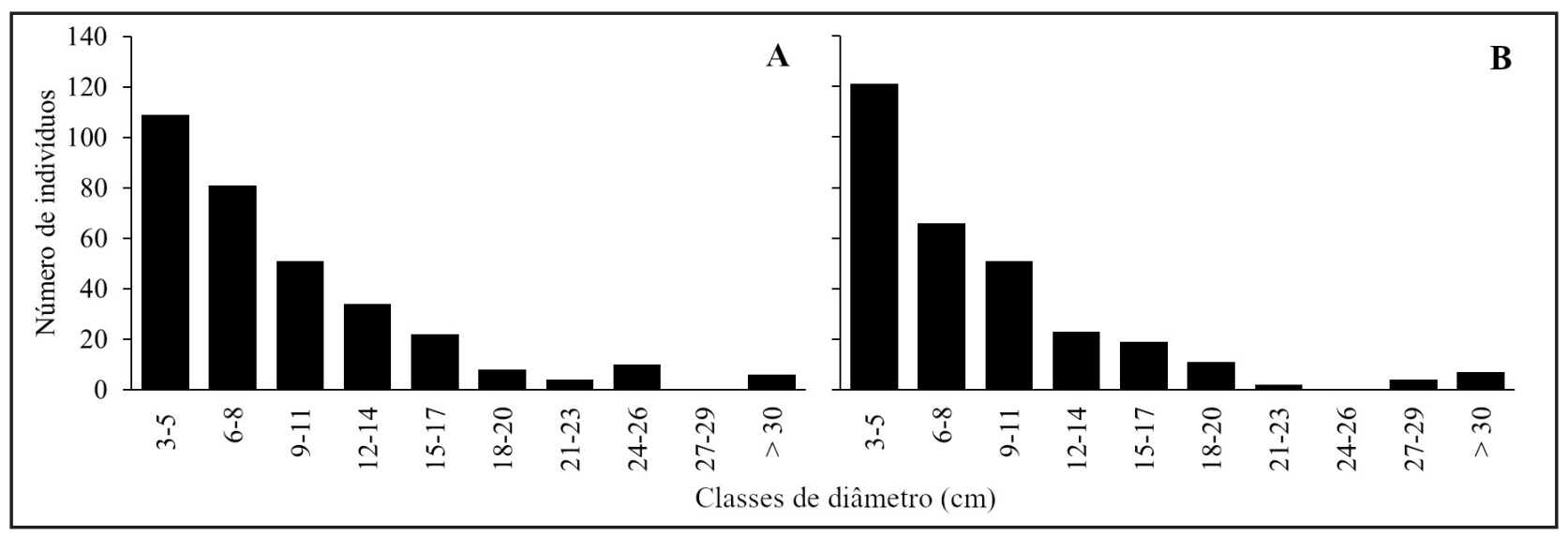

Fonte: Autores (2021)

No compartimento Gleissolo, Myrciaria tenella, a segunda espécie de maior importância neste ambiente apresentou cerca de 70\% dos indivíduos nas menores classes de diâmetro. A maior parte dos indivíduos se enquadrou na classe de DAP de até $5 \mathrm{~cm}$, evidenciando a necessidade de se adotar esse critério de inclusão ao se estudar estes ambientes (BARDDAL et al., 2004b). No compartimento Neossolo, os maiores valores de diâmetro foram representados principalmente por indivíduos de Araucaria angustifolia, com valores de DAP de 28 a 42,6 cm. Em geral, quando a comunidade apresenta distribuição diamétrica com tendência ao padrão "J" invertido, com grande número de indivíduos jovens em relação a indivíduos adultos, a população está estável e provavelmente crescendo (CONDIT et al., 1998). Esse resultado também 
foi encontrado em outras formações vegetais nos estudos de Silva et al. (2009) e Kuchla et al. (2015), avaliando florestas aluviais nos estados de Minas Gerais e Mato Grosso, respectivamente.

No compartimento Gleissolo foram observados dois estratos (Figura 3A). Entre 5 e 10 metros encontrava-se o estrato superior da floresta, sendo predominante a presença de Blepharocalyx salicifolius, Vitex megapotamica, Erythrina crista-galli, Gymnanthes klotschiana e Schinus terebinthifolia; e o inferior, abaixo dos 5 metros, composto por Myrciaria tenella, Daphnopsis racemosa, Myrrhinium atropurpureum, Allophylus edulis e Gymnanthes klotschiana. Cabe ressaltar que alguns indivíduos de Blepharocalyx salicifolius, Erythrina crista-gallie Gymnanthes klotschiana atingiram valores médios de até 12 metros de altura, mas por representarem uma menor densidade de árvores em relação às demais não configuram um estrato vertical na floresta.

Figura 3 - Diagrama de estratificação vertical para as espécies amostradas nos compartimentos Gleissolo (A) e Neossolo (B), em ordem decrescente do valor de importância

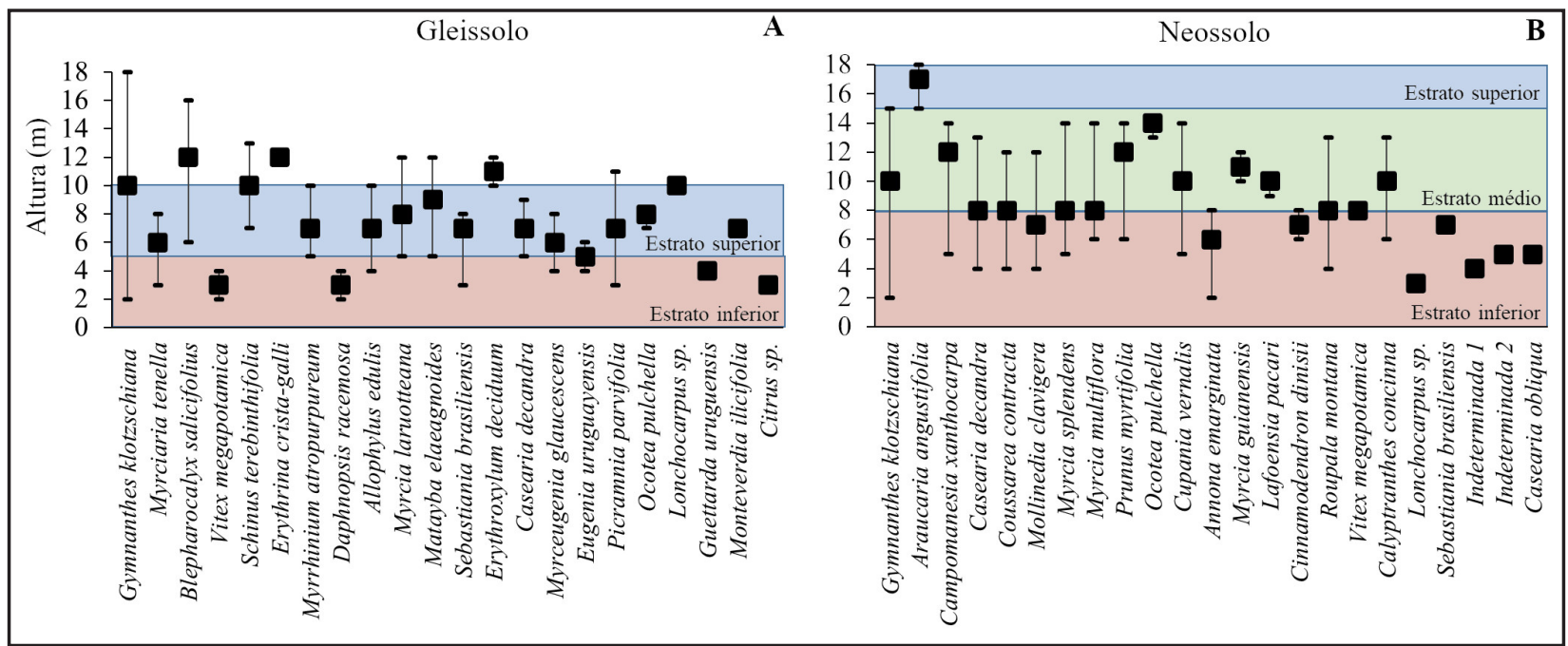

Fonte: Autores (2021)

Em que: *Quadrados representam a altura média e traços a mínima e máxima registradas para cada espécie; um quadrado indica que a espécie foi amostrada por um indivíduo. 
Para o compartimento Neossolo, foram observados três estratos distintos, com a maioria das espécies concentradas nos estratos intermediário e inferior (Figura 3B). O estrato superior, situado entre 15 e 18 metros, foi composto principalmente por Araucaria angustifolia e alguns indivíduos de Gymnanthes klotzschiana. O segundo estrato, intermediário, está situado entre 8 e 14 metros de altura, colonizado por Gymnanthes klotzschiana, Ocotea pulchella, Lafoensia pacari, Myrcia guianensis, Campomanesia xanthocarpa e Casearia decandra, e, um estrato inferior, abaixo de 8 m, compreendendo as espécies Coussarea contracta, Annona emarginata, Cinnamodendron dinisii e Calyptranthes concinna.

A estratificação vertical dos compartimentos demonstrou a especificidade da vegetação em cada classe de solo. De fato, a floresta aluvial já é bastante restritiva em termos de riqueza de espécies e desenvolvimento estrutural da vegetação. Mas, ao se compartimentar a fitotipia em função das características pedológicas, é possível observar que ela comporta ambientes mais ou menos seletivos, deixando clara a importância das variações do lençol freático na diferenciação da estrutura do componente arbóreo em pequena escala (SILVA et al., 2009). Apesar de dominada por Gymnanthes klotzschiana, a vegetação do compartimento Gleissolo possui apenas dois estratos verticais, provavelmente devido à maior saturação hídrica e acidez do solo, com baixa saturação por bases e elevados teores de alumínio trocável (SEGER et al., 2005), dificultando o estabelecimento e desenvolvimento da vegetação.

\section{CONCLUSÃO}

A composição florística e a estrutura do remanescente de floresta aluvial divergiram nas duas condições pedológicas avaliadas. Os compartimentos Neossolo e Gleissolo apresentaram baixa similaridade florística, embora Gymnanthes klotzschiana tenha sido a espécie dominante nas duas classes de solo, apresentando monodominância nesta floresta. Para Gleissolo houve o predomínio de espécies hidrófilas e higrófilas, com destaque para Myrciaria tenella, e, para o Neossolo, 
espécies mesófilas, como Araucaria angustifolia. A área avaliada apresentou baixa riqueza e diversidade de espécies, evidenciando a especificidade e o caráter restritivo dos ambientes aluviais, determinados pelas características pedológicas. Assim, é de suma importância compartimentar esses ambientes segundo suas características pedológicas para obter um entendimento mais detalhado da comunidade vegetal.

\section{REFERÊNCIAS}

ALVARES, C. A. et al. Köppen's climate classification map for Brazil. Meteorologische Zeitschrift, Stuttgart, v. 22, n. 6, p. 711-728, 2013. Disponível em: https://www.schweizerbart.de/papers/ metz/detail/22/82078/Koppen_s_climate_classification_map_for_Brazil. Acesso em: 27 ago. 2019.

BARDDAL, M. L. et al. Fitossociologia do sub-bosque de uma Floresta Ombrófila Mista Aluvial, no Município de Araucária, PR. Ciência Florestal, Santa Maria, v. 14, n. 1, p. 35-45, 2004a. Disponível em: $\quad$ https://www.scielo.br/scielo.php?script=sci_arttext\&pid=S1980-50982004000100035. Acesso em: 18 set. 2019.

BARDDAL, M. L. et al. Caracterização florística e fitossociológica de um trecho sazonalmente inundável de floresta aluvial, em Araucária, PR. Ciência Florestal, Santa Maria, v. 14, n. 2, p. 3750, 2004b. Disponível em: https://www.scielo.br/pdf/cflo/v14n2/1980-5098-cflo-14-02-00037. pdf. Acesso em: 18 set. 2019.

BONNET, A. et al. Relações de bromeliáceas epifíticas com fatores ambientais em planícies de inundação do rio Iguaçu, Paraná, Brasil. Revista Floresta, Curitiba, v. 40, n. 1, p. 193-208, jan./ mar. 2010. Disponível em: https://revistas.ufpr.br/floresta/article/view/17110. Acesso em: 04 nov. 2019.

CONDIT, R. et al. Predicting population trends from size distributions: a direct test in a tropical tree community. The American Naturalist, Chicago, v. 152, n. 4, p. 495-509, oct. 1998. Disponível em: https://www.journals.uchicago.edu/doi/10.1086/286186. Acesso em: 10 mar. 2021.

CONNELL, J. H.; LOWMAN, M. D. Low-diversity tropical rain forests: some possible mechanisms for their existence. The American Naturalist, Chicago, v. 134, n. 1, p. 88-119, jul. 1989. Disponível em: https://www.journals.uchicago.edu/doi/pdf/10.1086/284967. Acesso em: 11 mar. 2021.

COSMO, N. L.; KUNIYOSHI, Y. S.; BOTOSSO, P. C. Anatomia da madeira de Sebastiania commersoniana (Baillon) Smith \& Downs (Euphorbiaceae): aspectos funcionais e ecológicos. Acta Botanica Brasilica, São Paulo, v. 24, n. 3, p. 747-755, 2010. Disponível em: https://www. scielo.br/pdf/abb/v24n3/v24n3a18.pdf. Acesso em: 20 nov. 2019.

CURCIO, G. R. et al. A floresta fluvial em dois compartimentos do rio Iguaçu, Paraná, Brasil. Revista Floresta, Curitiba, v. 37, n. 2, p. 125-147, maio/ago. 2007. Disponível em: https:// revistas.ufpr.br/floresta/article/view/8645. Acesso em: 20 set. 2019. 
CURCIO, G. R. et al. Compartimentação topossequencial e caracterização fitossociológica de um capão de Floresta Ombrófila Mista. Revista Floresta, Curitiba, v. 36, n. 3, p. 361-369, set./ dez. 2006. Disponível em: https://revistas.ufpr.br/floresta/article/view/7515. Acesso em: 22 set. 2019.

CURCIO, G. R. Relações entre geologia, geomorfologia, pedologia e fitossociologia nas planícies fluviais do rio Iguaçu, Paraná, Brasil. 2006. Tese (Doutorado em Engenharia Florestal) - Setor de Ciências Florestais, Universidade Federal do Paraná, Curitiba, 2006. Disponível em: https://acervodigital.ufpr.br/handle/1884/34416. Acesso em: 16 set. 2019.

DUFRÊNE, M.; LEGENDRE, P. Species assemblages and indicator species: the need for a flexible asymmetrical approach. Ecological Monographs, Washington, v. 67, n. 3, p. 345-366, aug. 1997. Disponível em: https://esajournals.onlinelibrary.wiley.com/doi/abs/10.1890/00129615(1997)067[0345:SAAIST]2.0.CO;2. Acesso em: 12 nov. 2019.

EISENLOHR, P. V. et al.(ed.). Fitossociologia no Brasil: métodos e estudos de casos. Viçosa: Ed. da UFV, 2015. v. 2.

FLORA do Brasil 2020. Rio de Janeiro: Jardim Botânico do Rio de Janeiro, [20--]. Disponível em: http://floradobrasil.jbrj.gov.br/reflora/listaBrasil/ConsultaPublicaUC/ ResultadoDaConsultaNovaConsulta.do\#CondicaoTaxonCP. Acesso em: 08 dez. 2019.

GALVÃO, F. Métodos de levantamento fitossociológico. In: A VEGETAÇÃo natural do Estado do Paraná. Curitiba: IPARDES, 1994. 20 p.

GAN, M. A. et al. Monção na América do Sul. São Bernardo do Campo: CPTEC/INPE, [20-]. Disponível em: http://climanalise.cptec.inpe.br/ rclimanl/revista/pdf/30anos/ganetal.pdf. Acesso em: 12 mar. 2021.

GONÇALVES, D. A. et al. Heterogeneity of a Tree Species Community in an Alluvial Area of Santa Catarina, Brazil. Floresta e Ambiente, Rio de Janeiro, v. 25, n. 2: e00096514, p. 1-10, 2018. Disponível em: https://www.scielo.br/scielo.php?pid=S2179-80872018000200128\&script=sci_ arttext. Acesso em: 17 jun. 2019.

IBGE. Manual técnico da vegetação brasileira. Rio de Janeiro: IBGE, 2012. (Série Manuais Técnicos em Geociências, n. 1).

KUCHLA, W. J. et al. Florística, estrutura horizontal e distribuição diamétrica em área de transição de cerrado e floresta aluvial no município de Campos de Júlio - MT. Ambiência, Guarapuava, v. 11, n. 1, p. 13-30, jan./abr. 2015. Disponível em: https://revistas.unicentro.br/ index.php/ambiencia/article/view/2437. Acesso em: 12 mar. 2021.

LOEBENS, R. et al. Partição da variação florístico-estrutural do componente arbóreo em uma Floresta Ombrófila Mista Aluvial no Sul do Brasil. Ciência Florestal, Santa Maria, v. 28, n. 2, p. 554, abr./jun. 2018. Disponível em: https://www.scielo.br/scielo.php?pid=S198050982018000200554\&script=sci_arttext. Acesso em: 17 jun. 2019.

LUCAS, E. J.; BÜNGER, M. O. Myrtaceae in the Atlantic forest: their role as a 'model' group. Biodiversity and Conservation, [s. I.], v. 24, n. 9, p. 2165-2180, 2015. Disponível em: https:// link.springer.com/article/10.1007/s10531-015-0992-7. Acesso em: 10 mar. 2021. 
MACHADO, S. do A. et al. Comparação dos parâmetros fitossociológicos entre três estratos de um fragmento de floresta ombrófila mista. Cerne, Lavras, v. 19, n. 3, p. 365-372, jul./set. 2013. Disponível em: https://www.scielo.br/scielo.php?pid=S0104-77602013000300002\&script=sci_ arttext\&tlng=pt. Acesso em: 21 nov. 2019.

NASCIMENTO, A. R. T.; RAMOS, P. H. X.; DALMASO, C. A. Estrutura e classificação de um remanescente de floresta ripária no município de Lages, SC. Ciência Florestal, Santa Maria, v. 21, n. 2, p. 209-218, abr./jun. 2011. Disponível em: https://periodicos.ufsm.br/cienciaflorestal/ article/view/3224. Acesso em: 21 nov. 2019.

PIJL, L. van der. Principles of dispersal in higher plants. 3rd ed. Berlin: Springer-Verlag, 1982. $402 \mathrm{p}$.

PILLAR, V. de P.; VÉLEZ, E. Extinção dos campos sulinos em unidades de conservação: um fenômeno natural ou um problema ético? Natureza \& Conservação, Rio de Janeiro, v. 8, n. 1, p. 84-86, jul. 2010. http://ecoqua.ecologia.ufrgs.br/Arquivos/Reprints\&Manuscripts/ Pillar\&Velez_2010_N\&C.pdf. Acesso em: 21 nov. 2019.

R CORE TEAM. R: a language and environment for statistical computing. Vienna: R Foundation for Statistical Computing, 2017. Disponível em: https://www.R-project.org. Acesso em: 18 nov. 2020.

ROBERTS, D. W. Labdsv: ordination and multivariate analysis for ecology. [S. I.: s. n.], 2019. Disponível em: http://cran.r-project.org/package=labdsv. Acesso em 18 nov. 2019.

RODERJAN, C. V. et al. As unidades fitogeográficas do estado do Paraná. Ciência \& Ambiente, Santa Maria, v. 13, n. 24, p. 75-92, jan./jun. 2002.

SANTOS, H. G. dos. et al. Sistema brasileiro de classificação de solos. 5. ed. rev. e ampl. Brasília, DF: Embrapa, 2018. 355 p.

SANTOS, R. D. dos et al. Manual de descrição e coleta de solo no campo. 7. ed. Viçosa: SBCS, 2015. $101 \mathrm{p}$.

SEGER, C. D. et al. Levantamento florístico e análise fitossociológica de um remanescente de Floresta Ombrófila Mista localizado no município de Pinhais, Paraná - Brasil. Revista Floresta, Curitiba, v. 35, n. 2, maio/ago. 2005. Disponível em: https://revistas.ufpr.br/floresta/article/ view/4617. Acesso em: 15 set. 2019.

SHEPHERD, G. J. Fitopac: versão 2.1. Campinas: UNICAMP, 2010. Disponível em: https:// pedroeisenlohr.webnode.com.br/fitopac/. Acesso em: 11 nov. 2018.

SHIBATA, M. et al. Effects of abiotic and biotic factors and stochasticity on tree regeneration in a temperate forest community. Écoscience, Québec, v. 17, n. 2, p. 137-145, 2010. Disponível em: https://www.tandfonline.com/doi/abs/10.2980/17-2-3163. Acesso em: 05 set. 2019.

SILVA, A. C. et al. Florística e estrutura da comunidade arbórea em fragmentos de floresta aluvial em São Sebastião da Bela Vista, Minas Gerais, Brasil. Revista Brasileira de Botânica, São Paulo, v. 32, n. 2, p. 283-297, abr./jun. 2009. Disponível em: https://www.scielo.br/scielo. php?pid=S0100-84042009000200008\&script=sci_abstract\&tlng=es. Acesso em: 08 mar. 2021. 
SOCHER, L. G.; RODERJAN, C. V.; GALVÃO, F. Biomassa aérea de uma Floresta Ombrófila Mista Aluvial no município de Araucária (PR). Revista Floresta, Curitiba, v. 38, n. 2, p. 245-252, abr./ jun. 2008. Disponível em: https://revistas.ufpr.br/floresta/article/view/11619. Acesso em: 12 ago. 2019.

STEHMANN, J. R. et al. (ed.). Plantas da Floresta Atlântica. Rio de Janeiro: Jardim Botânico do Rio de Janeiro, 2009. 516 p.

WHITMORE, T. C. Canopy gaps and two major groups of forest trees. Ecology, [s. I.], v. 70, n. 3, p. 536-538, jun.1989. Disponível em: https://www.jstor.org/stable/1940195?seq=1. Acesso em: 10 mar. 2021.

ZACARIAS, R. R. et al. Fitossociologia de dois trechos de floresta ombrófila densa aluvial em solos hidromórficos, Paraná, Brasil. Revista Floresta, Curitiba, v. 42, n. 4, p. 769-782, out./dez. 2012. Disponível em: https://revistas.ufpr.br/floresta/article/view/20409. Acesso em: 23 set. 2019.

\section{Contribuição de Autoria}

\section{1 - André Luís Pasdiora}

Biólogo, Me., Coordenador de Vigilância em Saúde Ambiental https://orcid.org/0000-0002-7716-8237•apasdiora@sms.curitiba.pr.gov.br

Contribuição: Conceituação, Curadoria de dados, Análise Formal, Investigação, Metodologia, Validação, Visualização de dados, Escrita - primeira redação

\section{2 - Daiane Cristina Dall Agnol Ceni}

Engenheira Florestal

https://orcid.org/0000-0002-3362-5221 • engdaianedallagnol@gmail.com

Contribuição: Análise Formal, Metodologia, Visualização de dados, Escrita - revisão e edição

\section{3 - Marília Borgo}

Bióloga, Dra.

https://orcid.org/0000-0003-4325-5137•maborgo@gmail.com

Contribuição: Conceituação, Investigação, Metodologia, Análise Formal 


\section{4 - Gustavo Ribas Curcio}

Engenheiro Agrônomo, Dr.

https://orcid.org/0000-0002-6426-9741•gustavo.curcio@embrapa.br

Contribuição: Conceituação, Investigação, Escrita - revisão e edição

\section{5 - Edilaine Duarte}

Engenheira Florestal, Me.

https://orcid.org/0000-0003-3623-5576• ediduarte10@gmail.com

Contribuição: Análise Formal, Metodologia, Validação, Visualização de dados, Escrita revisão e edição

\section{6 - Amanda Köche Marcon}

Engenheira Florestal, Dra.

https://orcid.org/0000-0002-9640-9825 • amandakoche@gmail.com

Contribuição: Análise Formal, Metodologia, Validação, Visualização de dados, Escrita revisão e edição

\section{7 - Franklin Galvão}

Engenheiro Florestal, Dr., Professor

https://orcid.org/0000-0002-1425-1607•fgalvao@ufpr.br

Contribuição: Conceituação, Investigação, Metodologia, Validação, Escrita - revisão e edição

\section{Como citar este artigo}

Pasdiora, A. L.; Ceni, D. C. D. A.; Borgo, M.; Curcio, G. R.; Duarte, E.; Marcon, A. K.; Galvão, F. Variações pedológicas influenciam a composição florístico-estrutural de florestas aluviais? Ciência Florestal, Santa Maria, v. 31, n. 4, p. 1671-1694, 2021. DOI 10.5902/1980509841666. Disponível em: https://doi.org/10.5902/1980509841666. 